University of Nebraska - Lincoln

DigitalCommons@University of Nebraska - Lincoln

4-15-1999

\title{
Structural and magnetic properties of nanocomposite Co:C films
}

M. Yu

University of Nebraska - Lincoln

Yi Liu

University of Nebraska-Lincoln, yliu@unl.edu

David J. Sellmyer

University of Nebraska-Lincoln, dsellmyer@unl.edu

Follow this and additional works at: https://digitalcommons.unl.edu/physicssellmyer

Part of the Physics Commons

Yu, M.; Liu, Yi; and Sellmyer, David J., "Structural and magnetic properties of nanocomposite Co:C films" (1999). David Sellmyer Publications. 80.

https://digitalcommons.unl.edu/physicssellmyer/80

This Article is brought to you for free and open access by the Research Papers in Physics and Astronomy at DigitalCommons@University of Nebraska - Lincoln. It has been accepted for inclusion in David Sellmyer Publications by an authorized administrator of DigitalCommons@University of Nebraska - Lincoln. 


\title{
Structural and magnetic properties of nanocomposite Co:C films
}

\author{
M. Yu, ${ }^{\text {a),b) }}$ Y. Liu, ${ }^{\text {c) }}$ and D. J. Sellmyer ${ }^{\text {b) }}$ \\ Center for Materials Research and Analysis, University of Nebraska, Lincoln, Nebraska 68588-0113
}

The structural and magnetic properties of Co:C nanocomposite films at room temperature were investigated as functions of annealing temperature, Co concentration, and film thickness. The as-deposited films, which were cosputtered from $\mathrm{Co}$ and $\mathrm{C}$ onto water-cooled glass substrates, are nonmagnetic amorphous $\mathrm{Co}-\mathrm{C}$ alloys. Hexagonal-close-packed (hcp) Co grains are formed in 100 $\mathrm{nm}$ films annealed at $300^{\circ} \mathrm{C}$ and most Co takes this structure when annealed at higher temperatures. The sizes of the Co grains range from 10 to $25 \mathrm{~nm}$, with larger grain size resulting from higher annealing temperature and higher Co concentration. With the increase of annealing temperature and Co concentration, the magnetic activation or switching volumes increase faster than the physical grain volumes, suggesting the increased exchange coupling between neighboring Co grains. The films with high coercivities have optimal combinations of large grain size and weak intergrain exchange coupling before a network-like structure is formed and the percolation threshold is reached. Coercivities of about 800 Oe were obtained in $100 \mathrm{~nm}$ films with annealing temperature of $400{ }^{\circ} \mathrm{C}$ and Co concentration of 60 at. \%. Higher coercivities, up to 1030 Oe, were obtained in films with reduced thickness and elevated annealing temperature. (c) 1999 American Institute of Physics. [S0021-8979(99)50708-1]

\section{INTRODUCTION}

The magnetic behavior of nanocomposite films has been extensively studied for their potential applications in magnetic recording ${ }^{1}$ and magnetoresistance effect. ${ }^{2,3} \mathrm{Co}$ and $\mathrm{C}$ are immiscible and the metastable Co carbides $\left(\mathrm{Co}_{2} \mathrm{C}\right.$ and $\mathrm{Co}_{3} \mathrm{C}$ ) decompose easily into $\mathrm{Co}$ and $\mathrm{C}^{4}$ In fact the macroscopic interdiffusion coefficient between $\mathrm{Co}$ and $\mathrm{C}$ is negative. ${ }^{5} \mathrm{Co}: \mathrm{C}$ composite films therefore form a good system to investigate the magnetic properties of nanostructured Co particles. Hayashi et al. proposed this system for potential ultrahigh density magnetic recording since $\mathrm{C}$ can provide good isolation between neighboring Co particles to reduce the intergrain exchange interaction. ${ }^{6}$

Activation volume (or switching volume) $V^{*}$ is the unit volume of magnetic moments switching together in magnetization reversal. For Stoner-Wohlfarth particles (singledomain particle with uniaxial anisotropy and coherent rotation) with volume $V$, information on the intergrain exchange interaction can be inferred from the comparison between $V^{*}$ and $V$ under low field approximation $\left(H_{c} \ll H_{A}\right.$, where $H_{c}$ is the coercivity and $H_{A}$ is the uniaxial anisotropy field). ${ }^{7} V^{*}$ $\gg V$ means that several grains are exchange-coupled and switch together, $V^{*} \approx V$ means that grains switch almost independently, and $V^{*}<V$ means incoherent rotation. $V^{*}$ is therefore the effective volume in magnetization reversal and controls the thermal stability ${ }^{8}$ and noise ${ }^{9}$ of magnetic recording media.

Nanostructured magnetic particles usually have grain sizes much smaller than the critical single-domain particle size and can be approximated by Stoner-Wohlfarth model.

\footnotetext{
a)Electronic mail: myu@unlinfo.unl.edu

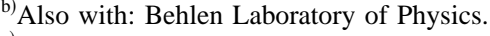

${ }^{c}$ Also with: Department of Mechanical Engineering.
}

$V^{*}$ can be determined from magnetic viscosity $(S)$ and irreversible susceptibility $\left(\chi_{\text {irr }}\right)$ measurements: $:^{10}$

$$
V^{*}=k_{B} T \chi_{\mathrm{irr}} / M_{s} S
$$

where $T$ is the temperature and $M_{s}$ is the saturation magnetization.

Generally in nanocomposite magnetic films, $H_{c}$ increases with increasing grain volume $V$ when the grains are isolated and exchange decoupled. However if $V$ increases to such an extent that leads to the contact and strong exchange interaction between neighboring grains, an effective multidomain structure is formed and $H_{c}$ will decrease rapidly with increasing $V$. When the grains have just started to contact each other and form a network-like structure, it is said that the percolation threshold is reached. Coercivity usually peaks near the percolation threshold. ${ }^{1}$

In this article we report the structural and magnetic properties of $\mathrm{Co}: \mathrm{C}$ nanocomposite films prepared by cosputtering and postannealing. The effects of annealing temperature, Co concentration, and film thickness on coercivity, saturation magnetization, physical grain volume, and activation volume are discussed. The effect of film thickness has become quite important because in extremely high density recording the film thickness has been reduced to about $15 \mathrm{~nm},{ }^{11}$ which is comparable with the grain size.

\section{EXPERIMENTAL METHODS}

The Co:C films were cosputtered from a Co target and a graphite target onto water-cooled 7095 glass substrates. The base pressure was better than $3 \times 10^{-7}$ Torr and Ar pressure was 10 mTorr. The Co:C layers are 5-100 nm thick with Co concentration varying from 50 to 80 at. \%, and are protected by $20 \mathrm{~nm} \mathrm{C}$ underlayer and overcoat. The as-deposited films were postannealed in vacuum at various temperatures 


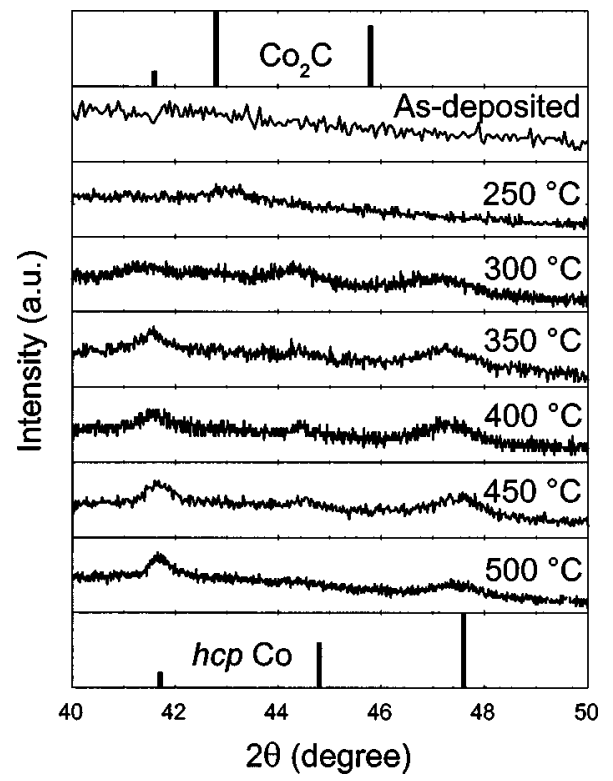

FIG. 1. XRD patterns of $100 \mathrm{~nm} \mathrm{Co:C} \mathrm{films} \mathrm{with} 60$ at. $\%$ Co concentration annealed at various temperatures $\left(T_{A}\right)$.

for two hours. The structural information was obtained from $\mathrm{x}$-ray diffraction (XRD) and transmission electron microscopy (TEM) analyses. The hcp Co grain sizes of $100 \mathrm{~nm}$ films were estimated from the (100) peak width in XRD patterns by the Scherrer formula. ${ }^{12}$ The magnetic measurements at room temperature were performed on an alternating gradient force magnetometer with the applied field parallel to the film plane. $V^{*}$ was calculated from Eq. (1).

\section{RESULTS AND DISCUSSION}

Figure 1 shows the annealing-temperature $\left(T_{A}\right)$ effect on the XRD patterns of $100 \mathrm{~nm} \mathrm{Co:C} \mathrm{films} \mathrm{with} 60$ at. \% Co concentration. The as-deposited films are amorphous $\mathrm{Co}-\mathrm{C}$ alloys as indicated in Fig. 1. Magnetic measurements show that they are nonmagnetic. This is in agreement with their amorphous structure. The $\mathrm{Co}_{2} \mathrm{C}$ phase is formed as the majority phase at $T_{A}=250^{\circ} \mathrm{C}$. As $T_{A}$ increases, $\mathrm{Co}_{2} \mathrm{C}$ starts to decompose and isotropically oriented hcp Co crystallites are formed. TEM analysis confirms that $\mathrm{Co}_{2} \mathrm{C}$ is the majority phase in films annealed at $250^{\circ} \mathrm{C}$, and that hcp Co is the main crystalline phase in films annealed at $350{ }^{\circ} \mathrm{C}$. Figure 2 shows the high-resolution TEM pictures of a $100 \mathrm{~nm}$ film with 60 at. \% Co concentration annealed at $350{ }^{\circ} \mathrm{C}$. It can be seen that the size of Co grains is in the order of $10 \mathrm{~nm}$ and some grains are in contact with each other. These results agree with other groups' work. ${ }^{4,13}$

Saturation magnetization $M_{s}$, coercivity $H_{c}$, grain volume $V$, and activation volume $V^{*}$ of $100 \mathrm{~nm}$ Co:C films with 60 at. \% Co concentration are plotted in Fig. 3 as a function of annealing temperature $T_{A} \cdot M_{s}$ increases steadily as $T_{A}$ increases from 250 to $350^{\circ} \mathrm{C}$, then changes little with $T_{A}$. Because $\mathrm{Co}_{2} \mathrm{C}$ is nonmagnetic, $M_{s}$ directly indicates the amount of crystalline Co formed in the films. Thus it can be inferred from the $M_{s}$ data that there is a small amount of crystalline $\mathrm{Co}$ in films annealed at $250{ }^{\circ} \mathrm{C}$. And as $T_{A}$ increases, more crystalline Co is formed until $T_{A}$ reaches

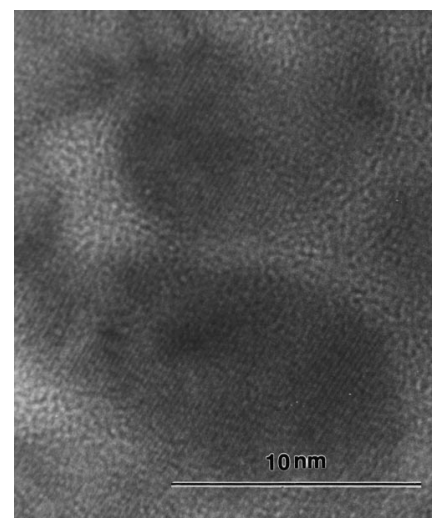

FIG. 2. High-resolution TEM picture of a $100 \mathrm{~nm} \mathrm{Co:C} \mathrm{film} \mathrm{with} 60$ at. $\%$ Co concentration annealed at $350{ }^{\circ} \mathrm{C}$.

$400{ }^{\circ} \mathrm{C}$, when $\mathrm{Co}_{2} \mathrm{C}$ has decomposed completely. Again this is consistent with the structural analysis discussed above.

Figure 3 also shows that with increasing $T_{A}, V$ and $V^{*}$ increase, while $H_{c}$ first increases then decreases. The grain sizes estimated from the Scherrer formula range from 10 to $20 \mathrm{~nm}$, which are much less than the film thickness. Spherical approximation is therefore used to estimate $V . H_{c}$ reaches the maximum of about 800 Oe near $T_{A}=300{ }^{\circ} \mathrm{C}$. The increase of $V$ is caused by both the increase of the amount of crystalline $\mathrm{Co}$ and the growth of existing Co grains. But further increase of $V$ brings the neighboring Co grains into contact. So near $T_{A}=300^{\circ} \mathrm{C}$ strong intergrain exchange coupling is developed and the percolation threshold is reached. This explains why the difference between $V^{*}$ and $V$ increases faster than $V$ with increasing $T_{A}$ when $T_{A}$ $>300{ }^{\circ} \mathrm{C}$. Now the $T_{A}$ dependence of $H_{c}$ can be understood. At low $T_{A}, V$ and therefore $H_{c}$ increase with increasing $T_{A}$. At high $T_{A}, H_{c}$ decreases due to the formation of effective multidomain structure, as the percolation threshold is passed with increasing $T_{A}$.

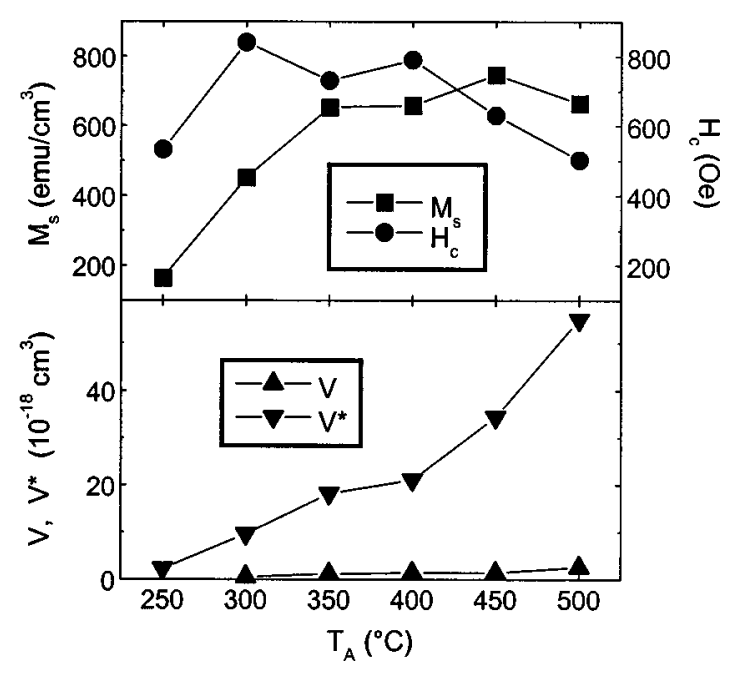

FIG. 3. $M_{s}, H_{c}, V$, and $V^{*}$ of $100 \mathrm{~nm} \mathrm{Co:C} \mathrm{films} \mathrm{with} 60$ at. $\%$ Co concentration annealed at various temperatures $\left(T_{A}\right)$. 


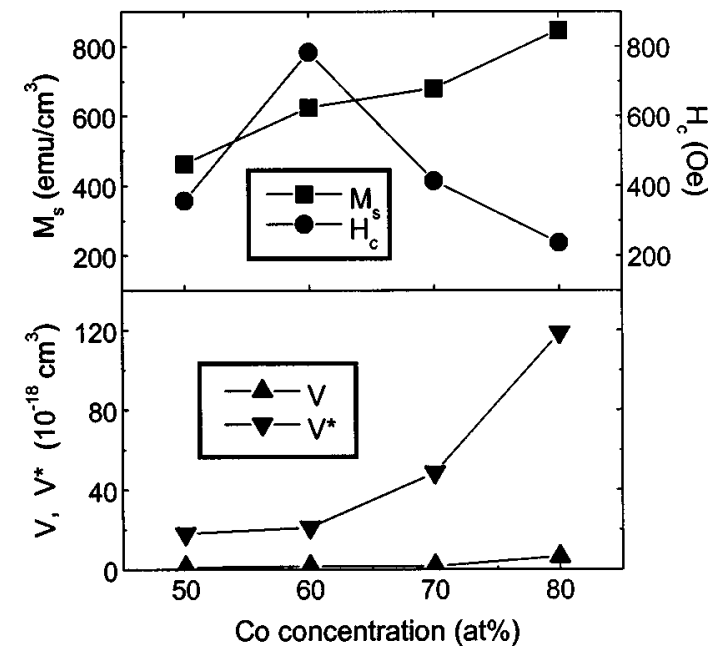

FIG. 4. $M_{s}, H_{c}, V$, and $V^{*}$ of $100 \mathrm{~nm} \mathrm{Co:C} \mathrm{films} \mathrm{annealed} \mathrm{at} 400{ }^{\circ} \mathrm{C}$ with various Co concentrations.

In Fig. 4, $M_{s}, H_{c}, V$, and $V^{*}$ of $100 \mathrm{~nm} \mathrm{Co:C} \mathrm{films}$ annealed at $400{ }^{\circ} \mathrm{C}$ are plotted as a function of Co concentration. As expected, $M_{s}$ increases almost linearly with the increase of Co concentration. $V$ and $V^{*}$ also increase, but $V^{*}$ increases much faster than $V$ when Co concentration is higher than 60 at. \%, suggesting that near this point strong intergrain exchange coupling occurs and the percolation threshold is reached. In Co:C films the 60 at. \% Co concentration corresponds to 57 vol. \% Co concentration, which is very close to the percolation threshold of $\sim 55 \mathrm{vol}$. $\%$ found in $\mathrm{Fe}: \mathrm{SiO}_{2}$ system. ${ }^{1}$ This result explains why at Co concentration of 60 at. $\% H_{c}$ reaches the maximum value of $790 \mathrm{Oe}$ and from another aspect strengthens our reasoning of the $V$ and $V^{*}$ dependence of $H_{c}$ discussed above.

Figure 5 shows the film thickness dependence of $H_{c}$ in Co:C films with 60 at. $\%$ Co concentration annealed at various temperatures. The maximum $H_{c}$ and therefore the percolation threshold occur in thinner film thickness when annealed at higher temperatures, indicating that in thinner films larger grains can be grown near the percolation threshold. This is understandable because the number of neighboring grains is reduced and percolation is formed only in a twodimensional plane when the film thickness is comparable with the grain size. Similar results have been reported in Co:Ag granular systems. ${ }^{14}$ Moreover, the larger grains formed near the percolation threshold due to higher annealing temperature also lead to higher maximum $H_{c}$ values. The highest $H_{c}$ value of 1030 Oe was obtained in $20 \mathrm{~nm}$ films annealed at $450{ }^{\circ} \mathrm{C}$. The films annealed at $550{ }^{\circ} \mathrm{C}$ is an exception, in which the maximum $H_{c}$ is smaller than that of the films annealed at $450{ }^{\circ} \mathrm{C}$. The reason is that the percolation threshold occurs at film thickness of about $5 \mathrm{~nm}$. Even with large lateral grain size, the restriction in the film thickness still reduces the grain volume and consequently the value of maximum $H_{c}$.

\section{CONCLUSIONS}

Nanostructured hcp Co particles with grain sizes ranging from 10 to $25 \mathrm{~nm}$ can be formed in Co:C composite films

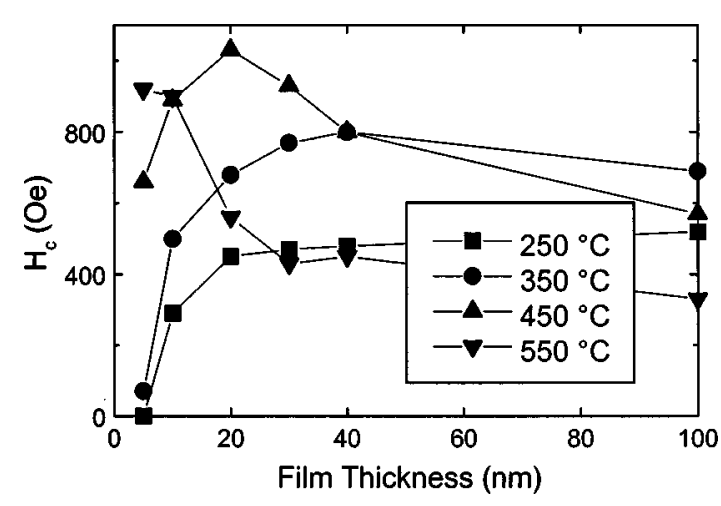

FIG. 5. Film thickness dependence of $H_{c}$ of Co:C films with 60 at. \% Co concentration annealed at various temperatures.

upon appropriate annealing. Both higher annealing temperature and higher Co concentration result in larger grain size and stronger intergrain exchange coupling. High coercivities are developed in films with large grain and weak intergrain exchange coupling near the percolation threshold. By reducing the film thickness and increasing the annealing temperature, larger grain size and therefore higher coercivity can be obtained near the percolation threshold. This result is especially useful for the development of extremely high density recording media as the film thickness has been reduced to about $15 \mathrm{~nm}$. The highest coercivity of $1030 \mathrm{Oe}$ was obtained in $20 \mathrm{~nm} \mathrm{Co:C} \mathrm{films} \mathrm{with} 60$ at. \% Co concentration annealed at $450{ }^{\circ} \mathrm{C}$.

\section{ACKNOWLEDGMENTS}

This work is supported by NSIC, NSF/DMR-9623992, and CMRA.

${ }^{1}$ C. L. Chien, J. Appl. Phys. 69, 5267 (1991).

${ }^{2}$ A. E. Berkowitz, J. K. Mitchell, M. J. Carey, A. P. Young, S. Zhang, F. E. Spada, F. T. Parker, A. Hutten, and G. Thomas, Phys. Rev. Lett. 68, 3745 (1992).

${ }^{3}$ J. Q. Xiao, J. S. Jiang, and C. L. Chien, Phys. Rev. Lett. 68, 3749 (1992).

${ }^{4}$ T. J. Konno and R. Sinclair, Acta Metall. Mater. 42, 1231 (1994).

${ }^{5}$ H. L. Bai, E. Y. Jiang, C. D. Wang, and R. Y. Tian, J. Phys.: Condens. Matter 8, 8763 (1996)

${ }^{6}$ T. Hayashi, S. Hirono, M. Tomita, and S. Umemura, Nature (London) 38, 772 (1996).

${ }^{7}$ D. J. Sellmyer, M. Yu, and R. D. Kirby, Nanostruct. Mater. (in press).

${ }^{8}$ M. Yu, M. F. Doerner, and D. J. Sellmyer, IEEE Trans. Magn. 34, 1534 (1998).

${ }^{9}$ K. Yamanaka, T. Yamamoto, K. Tanahashi, N. Indaba, Y. Uesaka, and M. Fatamoto, J. Magn. Magn. Mater. 152, 441 (1996).

${ }^{10}$ R. Street and J. C. Woolley, Proc. Phys. Soc. London, Sect. A 62, 562 (1949)

${ }^{11}$ C. Tsang, T. Lin, S. MacDonald, M. Pinarbasi, N. Robertson, H. Santini, M. Doerner, T. Reith, L. Vo, T. Doila, and P. Arnett, IEEE Trans. Magn. 33, 2866 (1997).

${ }^{12}$ B. D. Cullity, Elements of X-ray Diffraction, 2nd ed. (Addison-Wesley, Reading, MA, 1978), p. 102.

${ }^{13}$ J.-J. Delaunay, T. Hayashi, M. Tomita, and S. Hirono, J. Appl. Phys. 82, 2200 (1997).

${ }^{14}$ A. Butera, T. J. Klemmer, and J. A. Barnard, J. Appl. Phys. 83, 4855 (1998). 